\title{
Facts about Minerals ${ }^{1}$
}

R. Elaine Turner ${ }^{2}$

\section{What are minerals?}

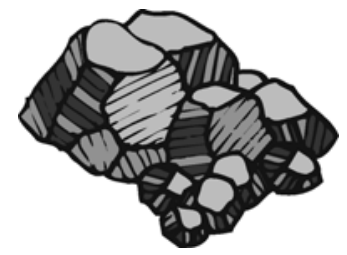

If the word "mineral" makes you think of rocks, you're right! Minerals are substances like calcium, phosphorus, iron, and zinc that are found in rocks and the soil. They also are needed for optimal nutrition.

There are 16 different minerals that are known to be needed in our diets. Several other minerals may be needed in very small amounts.

\section{What are the different types of minerals?}

Minerals are grouped as macrominerals and trace minerals. Macrominerals are those found in larger quantities in the body and needed in larger amounts in the diet. Calcium and phosphorus are two of the seven macro-minerals that we need in our diets.

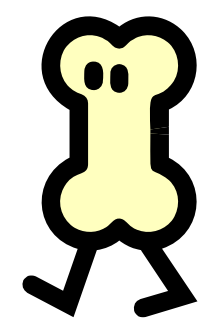

Trace minerals are found in small quantities in the body and are needed in small amounts in the diet. We need to include nine trace minerals in our diets, including iron and zinc.

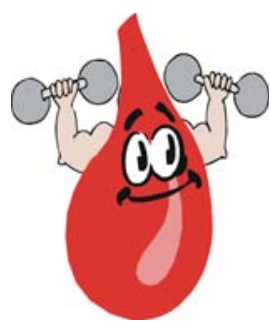

The following table lists the 16 minerals that we need in our diets.

\begin{tabular}{|c|c|}
\hline \multicolumn{2}{|c|}{ Types of Minerals } \\
\hline Macrominerals & Trace Minerals \\
\hline Sodium & Iron \\
\hline Potassium & Zinc \\
\hline Chloride & lodide \\
\hline Calcium & Selenium \\
\hline Phosphorus & Copper \\
\hline Magnesium & Fluoride \\
\hline Sulfur & Chromium \\
\hline & Molybdenum \\
\hline & Manganese \\
\hline
\end{tabular}

1. This document is FCS8809, one of a series of the Department of Family, Youth and Community Sciences, Florida Cooperative Extension Service, Institute of Food and Agricultural Sciences, University of Florida. Publication date: December 2006. Please visit the EDIS Web site at http://edis.ifas.ufl.edu.

2. R. Elaine Turner, PhD, RD, associate dean, College of Agricultural and Life Sciences, Institute of Food and Agricultural Sciences, University of Florida, Gainesville, 32611. 


\section{What do minerals do in the body?}

Minerals work in two ways in the body.

Many minerals support body cells and structures. For example, calcium and

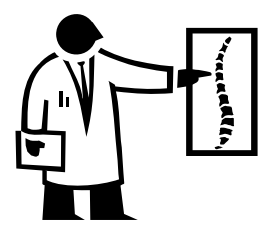
phosphorus help build bones, and iron is an essential part of red blood cells.

Minerals also work to regulate many body processes. Sodium and potassium are important to nervous system function. Chromium helps keep blood glucose levels normal. The trace mineral selenium works with vitamin $\mathrm{E}$ as an antioxidant: something that prevents cells from being damaged by oxygen.

\section{Where are minerals found in foods?}

Sometimes people think that minerals are only found in animal products because they know that milk is a good source of calcium and meat is rich in iron. However, all of the food groups have foods rich in minerals.

Fruits and vegetables are good sources of potassium. Whole grains are rich in magnesium, selenium, and chromium. Nuts and seeds are good

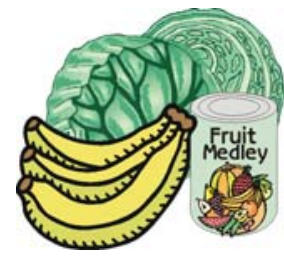
sources of copper and manganese. Red meats are particularly good sources of iron and zinc.

It's important to eat a variety of foods from each of the food groups in order to get all of the minerals in your diet.
Are animal products better sources of minerals than plant foods?

Certain minerals (like iron and zinc) tend to be better absorbed by the body from animal foods than from plant foods. Fiber, phytate, and oxalate, which are

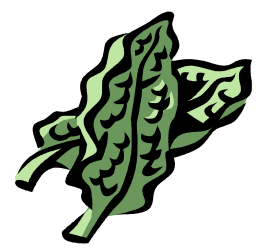
found mainly in whole grains, vegetables, and legumes, reduce absorption of some minerals.

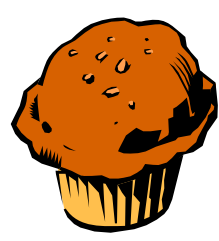
Still, plant foods are important sources of many minerals, so diets rich in a variety of plant foods can provide adequate amounts of minerals.

\section{Does food processing affect the mineral content of foods?}

Minerals are much more stable than vitamins in food. They generally remain in the food even after cooking, canning, or freezing.

Processing does affect the balance of sodium and potassium in vegetables. Fresh vegetables are rich in potassium and naturally low in sodium. Canned vegetables are usually higher in sodium from added salt.

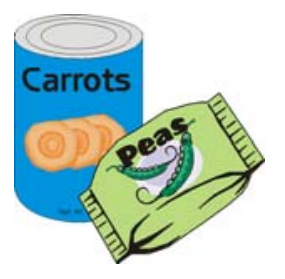

\section{How much of each mineral do I need each day?}

The amount of minerals we need is actually very small - much smaller than the amounts of carbohydrates, protein, and fats required for a healthy diet. Adults need about 1,000 milligrams of calcium per day, but only about 10 to 15 milligrams of iron and zinc per day. 
We need less than 100 micrograms of chromium, selenium, and molybdenum. To give you an idea of how little this is, a teaspoon of selenium would satisfy the daily needs of over 90,000 adults!

The Daily Value for a mineral on a food label shows you what percent of a typical healthy adult's need for that vitamin is provided by the food. For example, an 8-ounce glass of fat-free milk provides $30 \%$ of the Daily Value for calcium.

\section{Should I take supplements to get the minerals I need?}

It's possible to get all the minerals you need by making healthy food choices from all of the groups in MyPyramid. But there are some situations where supplements may be needed.

- Women in their childbearing years may find it hard to get all the iron they need from food.

- People who are allergic to milk or who are lactose intolerant may have a hard time getting enough calcium.

- Pregnant women should ask their physicians about the supplements that are right for them.

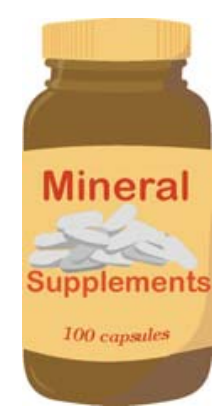

\section{Can large amounts of minerals be harmful?}

With minerals, as with many things in life, more is not necessarily better. Many minerals can be toxic in large doses, with side effects ranging from constipation to liver and kidney damage. Too much sodium and chloride may make it difficult to control blood pressure.

Scientists have set recommended maximum intakes for most minerals. Excessive mineral intake usually comes from high-dose supplements. That's why most people should choose supplements that contain no more than 100 to $150 \%$ of the Daily Value for each mineral.

Sometimes, taking a mineral supplement such as iron causes an upset stomach. If this occurs, try taking the supplement before bed, or use a slow-release supplement. 
If you currently are taking medications, you should check with your doctor or pharmacist to see if there are any reasons that you shouldn't take a mineral

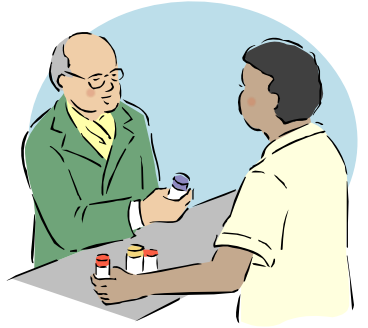
supplement. Also ask if you need to adjust the timing of your mineral supplements and other medications.

Some minerals can interfere with how well a medication works in the body. On the other hand, some medications can interfere with how well the body uses a mineral. That's why it's important to ask your doctor or pharmacist before taking a mineral supplement.

\section{Where can I get more information on minerals?}

The Family and Consumer Sciences (FCS) agent at your local county Extension office may have more written information and nutrition classes for you to attend. Also, a registered dietitian (RD) can provide reliable information to you.

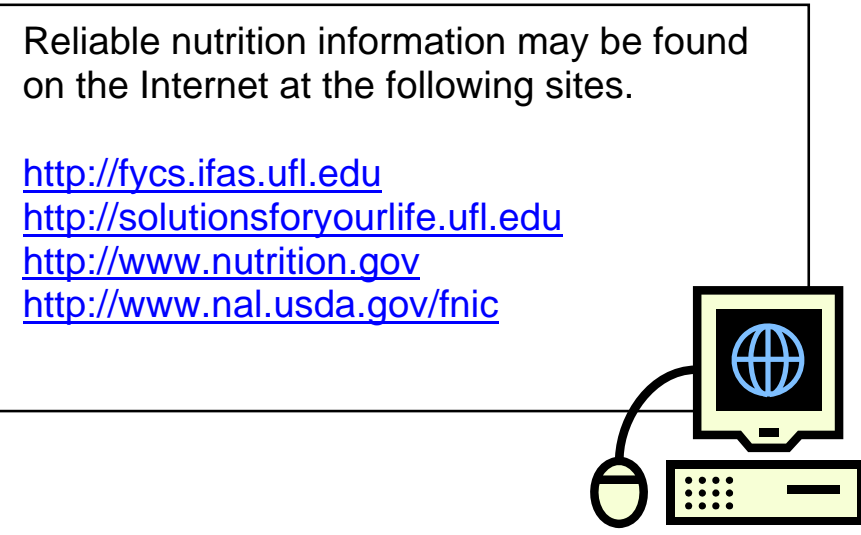

\section{WARNING!!!}

Do NOT consume more than these amounts from a combination of food and supplements!

Calcium $2,500 \mathrm{mg}$

Phosphorus $4,000 \mathrm{mg}$

Magnesium $350 \mathrm{mg}$

Iron $45 \mathrm{mg}$

Zinc $40 \mathrm{mg}$

Boron $20 \mathrm{mg}$

Manganese $11 \mathrm{mg}$

Copper $10 \mathrm{mg}$

Fluoride $10 \mathrm{mg}$

Molybdenum . $.2 \mathrm{mg}$

Vanadium $1.8 \mathrm{mg}$

lodide $1.1 \mathrm{mg}$

Nickel $1.0 \mathrm{mg}$

Selenium $.0 .4 \mathrm{mg}$

$\mathrm{mg}=$ milligrams 